\title{
BMJ Open Cardiometabolic risk factors and early indicators of vascular dysfunction: a cross-sectional cohort study in South African adolescents
}

\author{
Boitumelo Prescilla Letswalo, ${ }^{1}$ Karin Schmid-Zalaudek (D) , ${ }^{2}$ Bianca Brix, ${ }^{2}$ \\ Edna Ngoakoana Matjuda, ${ }^{3}$ Fabian Klosz, ${ }^{2}$ Natalie Obernhumer, ${ }^{2}$ Michael Gaisl, ${ }^{2}$ \\ Godwill Azeh Engwa, ${ }^{1}$ Constance Sewani-Rusike, ${ }^{1}$ Per Morten Fredriksen, ${ }^{4}$ \\ Benedicta Nkeh-Chungag, ${ }^{1,3}$ Nandu Goswami ${ }^{2}$
}

To cite: Letswalo BP, SchmidZalaudek K, Brix B, et al. Cardiometabolic risk factors and early indicators of vascular dysfunction: a cross-sectional cohort study in South African adolescents. BMJ Open 2021;11:e042955. doi:10.1136/ bmjopen-2020-042955

- Prepublication history for this paper is available online. To view these files, please visit the journal online (http://dx.doi. org/10.1136/bmjopen-2020042955).

BPL and KS-Z contributed equally.

Received 21 August 2020

Revised 11 January 2021

Accepted 10 February 2021

Check for updates

(C) Author(s) (or their employer(s)) 2021. Re-use permitted under CC BY-NC. No commercial re-use. See rights and permissions. Published by BMJ.

For numbered affiliations see end of article.

Correspondence to

Dr Nandu Goswami;

nandu.goswami@medunigraz.at

\section{ABSTRACT}

Objectives Prevalence of child and adolescents' overweight and obesity in low- and middle-income countries has increased dramatically. Simultaneously, the incidence of pre-hypertension/hypertension is also increasing in children, which, in turn, predisposes these children to the risk of cardiovascular disease (CVD) in later life. The present study assessed cardiometabolic risk factors and early indicators of vascular dysfunction in adolescents from a low socio-economic rural area in South Africa.

Design Cross-sectional cohort study.

Setting The study was conducted in public schools in Mthatha, OR Tambo district municipality, Eastern Cape Province, South Africa.

Participants A total of 244 adolescents (188 females) of African ancestry aged 13-16 years were enrolled.

\section{Primary and secondary outcome}

measures Anthropometric and haemodynamic measures and pulse wave velocity (PWV) were related to overweight/obesity and hypertension. Blood markers of cardiometabolic syndrome were assessed as well as vascular function (via PWV).

Results One-third (33.0\%) of the adolescents exceeded the age and sex-specific body mass index percentiles for overweight ( $\geq 85$ th) or obesity ( $>95$ th) with a prevalence of $61.1 \%$ pre-hypertensives in this group. Overweight/ obesity and hypertension were associated with higher triglycerides (lean:overweight: $0.79<1.01 \mathrm{mmol} / \mathrm{L}$; normotensive:hypertensive: $0.82<0.89 \mathrm{mmol} / \mathrm{L}$ ). Fasting glucose was higher in hypertensive as compared to normotensive adolescents $(4.85>4.69 \mathrm{mmol} / \mathrm{L}, \mathrm{p}<0.05)$. PWV was elevated in $25.9 \%$ of the children and significantly correlated with asymmetric dimethylarginine and systolic blood pressure $(p<0.001)$

Conclusion Overweight/obesity and hypertension show a high prevalence in rural South African youth. Almost half of the studied adolescents are at risk for developing CVD. The high association between cardiometabolic risk factors and PWV further suggests that hypertension in adolescents may promote the progression of CVD in adulthood. Early detection of those at risk and the implementation of preventive strategies in underprivileged young people

\section{Strengths and limitations of this study}

- Novel study of cardiovascular risk in African adolescents.

- Cardiovascular risk assessed via vascular function and blood markers.

- Urgent need for preventive strategies against cardiovascular diseases.

More girls were studied than boys.

- Behavioural risk factors (eg, smoking, activity, eating habits) not studied.

is urgently needed to stop the progression of vascular damage and manifestation of CVD in rural African children.

\section{INTRODUCTION}

Childhood overweight/obesity has become a global socio-economic concern as the increasing prevalence rates are paralleled to the increasing number of non-communicable diseases. ${ }^{1-5}$ Childhood obesity is related to premature onset of several serious health complications, which often persist into adulthood. These include: hypertension, insulin resistance and type 2 diabetes, non-alcoholic fatty liver disease, respiratory and orthopaedic disorders, along with psychosocial difficulties and low quality of life. ${ }^{267}$

Low- and middle-income countries have experienced the most rapid increase in child and adolescent obesity. ${ }^{8}$ Between 1990 and 2015, the number of children with overweight/obesity in Africa increased from 4 to 10 million. ${ }^{23}$ In South Africa, for example, the prevalence of adolescents with overweight/obesity is $40.2 \% .^{8-11}$

Sub-Saharan African countries in general are also experiencing an exceptionally high and increasing prevalence of hypertension, the most important risk factor for cardiovascular disease (CVD). ${ }^{1812}$ Even in children and adolescents, 
increases in arterial blood pressure, mainly driven by obesity, and as a consequence of an obesogenic environment, unhealthy diet and reduced physical activity, is commonly seen. ${ }^{13}$ Estimates, however, vary largely: from pooled prevalence of $1 \%-5 \%{ }^{14}{ }^{15}$ globally up to point prevalence ratings of $25.5 \%$ adolescent hypertension/pre-hypertension in African countries. ${ }^{10}{ }^{16-19}$ In a substantial amount of affected children, (pre-)hypertension tracks into adulthood, resulting in atherosclerosis, left ventricular hypertrophy or other related CVD. ${ }^{20-23}$

Hypertension and endothelial dysfunction are closely connected. Endothelial cells, positioned at the interface between blood and tissue, respond quickly to local trauma or inflammation. ${ }^{24}$ Alterations in the endothelium can lead to endothelial dysfunction, a state in which the bioavailability of nitric oxide (NO) to blood vessels is reduced. ${ }^{25}$ Asymmetric dimethylarginine (ADMA) can alter the bioavailability of $\mathrm{NO}$ by competing with arginine for $\mathrm{NO}$ synthesis, therewith inhibiting the synthesis of NO. As a consequence, endotheliummediated vasomotor responses and anti-inflammatory properties are impaired. ${ }^{26}$ This is considered as the initial step towards vascular remodelling, atherosclerosis and/or cardiovascular or cerebrovascular disease. ${ }^{27}$

One of the earliest signs of vascular damage is arterial stiffness. Together with plasma ADMA, an indicator for endothelial (dys-)function, pulse wave velocity (PWV) is routinely used as a non-invasive measure of arterial stiffness. ${ }^{28}$ Significant changes in PWV are commonly observed after the fifth decade of life, though the age-related increase of PWV seems to be continuous, starting already at the early age of 6 years. ${ }^{28}{ }^{29}$ Higher PWV is usually observed in males, though accelerated values are also related to several cardiovascular risk factors. ${ }^{28}{ }^{29}$ Family history of CVD, elevated blood pressure and obesity have been reported to be associated with increased PWV, already in children and adolescents. ${ }^{28-32}$

Recent findings indicate a high prevalence of prehypertension/hypertension (42.16\%) and overweight/ obesity (19.28\%) in South African children, even as young as $6-9$ years. ${ }^{33}$

The present study focused on early indicators of vascular dysfunction assessed by PWV and serum plasma ADMA in adolescents. Cardiovascular and metabolic risk factors along with anthropometric and haemodynamic measures were assessed in overweight/obese and pre-hypertensive/hypertensive adolescents in low-income and low-resource settings. Early detection of subclinical cardiovascular dysfunction is beneficial, as initiation of early treatment can prevent the progression and clinical manifestation of CVD in later life.

\section{METHODS}

\section{Study design}

The study was conducted as a cross-sectional cohort study in Mthatha area, in the OR Tambo district municipality, Eastern Cape Province, South Africa. The sample was drawn from adolescents of low socio-economic families, representative of populations living in rural areas of South Africa. Information about the study including the

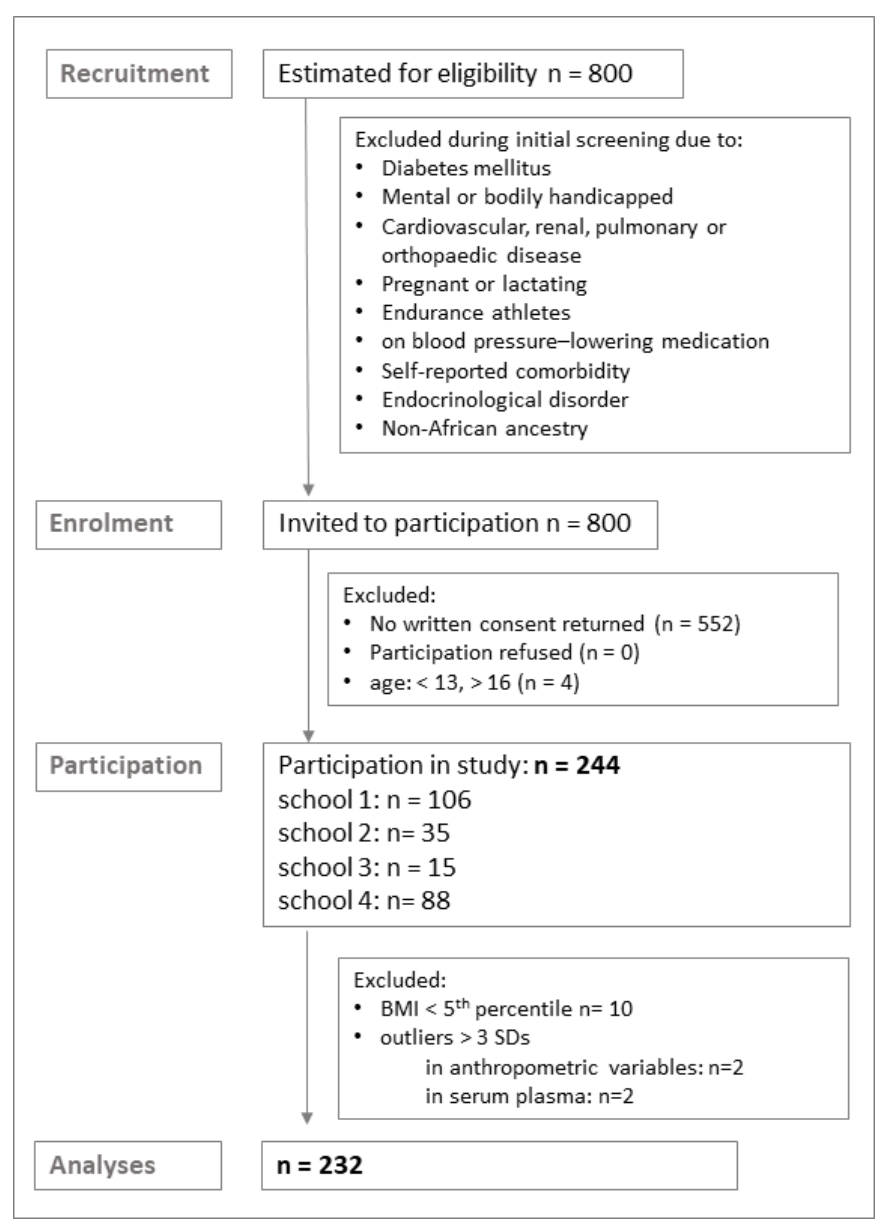

Figure 1 STROBE statement for study participation. BMI, body mass index; STROBE, Strengthening the Reporting of Observational Studies in Epidemiology.

consent form were distributed in four schools covering classes with children of eligible age $(n=800)$. Male and female adolescents of African ancestry aged 13-16 years, free from any chronic cardiovascular, renal, pulmonary and orthopaedic disease were included in the study. Pregnant, lactating, ill, physically handicapped, endurance athletes, individuals on blood pressure lowering medication, having any self-reported comorbidity, cardiovascular or endocrinological disorder and individuals of nonAfrican ancestry were excluded (figure 1).

\section{Sample size calculations}

Sample size calculations were based on previous research in this area assuming a medium effect size considering the prevalence of overweight/obesity in this area. ${ }^{10}$ For prevalence calculations based on $\chi^{2}$ tests, the estimated sample size (considering $\alpha=0.05$ and $1-\beta=0.95$ ) was 65 participants and for comparisons within an analysis of variances (ANOVA) (normotensive/hypertensive, overweight/obese) 60 participants in each group.

\section{Patient and public involvement}

No patients were involved. 


\section{Data collection and anthropometric measurements}

Demographic data including age, sex, height, weight and anthropometric measures, ${ }^{34}$ were collected by trained fieldworkers. For ethical purposes, female fieldworkers performed measurements on female participants while male fieldworkers assessed male participants. Subjects were barefoot and in minimal clothing. Waist, hip, thigh, calf, ankle and mid-upper arm circumferences were measured using an anthropometric tape and height was assessed using a wall-mounted Harpenden stadiometer to the nearest $0.1 \mathrm{~cm}$. Weight was measured using a wireless weight scale (Tanita body composition scale). The Tanita device also calculated body mass index (BMI) and body fat percentage. Age and gender-specific International Obesity Task Force percentile curves were used to classify BMI as: underweight: $<5$ th percentile, normal weight: > 5 th $<85$ th percentile, overweight: $\geq 85$ th $<95$ th percentile and obese: $\geq 95$ th percentile. ${ }^{35}$

\section{Blood pressure measurements}

Following a 5-minute rest in a quiet room, sitting blood pressure was measured automatically at 2-minute intervals using an automated sphygmomanometer (HBP-1100; Omron Healthcare Co.) and arm-size appropriate cuffs. An average of three blood pressure (BP) readings was then converted to BP percentiles for age, sex and height according to BP percentile guidelines for children (Centre for Disease Control and Prevention-National Health and Nutrition Examination Survey) ${ }^{36}$ Participants were classified as normotensive (NT: systolic BP (SBP) and diastolic BP $(\mathrm{DBP})<90$ th percentile), pre-hypertensive (preHT: SBP and DBP $>90$ th $<95$ th percentile or SBP $/ \mathrm{DBP}$ $\geq 120 / 80 \mathrm{~mm} \mathrm{Hg}$ ) or hypertensive (HT: SBP and/or DBP $\geq 95$ th percentile). Mean arterial pressure (MAP) was calculated using the formula: $\mathrm{MAP}=(\mathrm{SBP}+(2 \times \mathrm{DBP})) / 3$.

\section{Assessment of vascular functions}

Pulse wave velocity was measured using the Vicorder device (SMT medical GmbH \& Co. KG, Germany). Participants remained in a supine position for $10 \mathrm{~min}$ prior to measurements. A standard $10 \mathrm{~cm}$ pressure cuff was placed on the upper right thigh as high as possible towards the crotch while a $7 \mathrm{~cm}$ pressure cuff was wrapped around the wrist of the same arm. The cuff was closed tight enough to assure a good coupling of the cuff to the femoral artery. The right common carotid artery pulse was palpated on the centre between the base of the neck and chin, where a neck band with an attached neck pressure cuff was placed around the neck, thus positioning the cuff bladder exactly over the palpated carotid artery pulse. Pressure lines were attached to the cuffs and PWV was determined.

\section{Blood collection and biochemical analysis}

Blood samples were collected following an overnight fast. Plasma was obtained after centrifugation and fasting glucose (FG), triglycerides (TG), total cholesterol (TC), high-density lipoprotein cholesterol (HDL-c), nonesterified free fatty acids (NEFA), fasting insulin, NOs and ADMA were determined. HDL-c, NEFA, insulin and ADMA were measured with ELISA kits while FG, TG and TC were determined using a COBAS 501/502 panel/ system (Roche Diagnostics, USA).

\section{Statistical analysis}

Data distribution was examined by Shapiro-Wilks test, which indicated deviation from normal distribution for TGs, insulin, FG and NOs. These measurements were then log-transformed for metric statistics. Descriptive statistics are presented as mean \pm SD. Prevalence rates were calculated by $\chi^{2}$ tests, and group differences (between overweight/obese vs lean, normotensive vs prehypertensive/hypertensive adolescents) were assessed by analyses of variances (ANOVA) or multivariate analyses of variances (MANOVA) or Student's t-test. A p value $<0.05$ was considered statistically significant. Anthropometric measures, haemodynamic and serum plasma parameters were treated as dependent variables in group-wise analyses. All data were also analysed in a sex-specific manner. Considering anthropometric parameters, we observed only differences in neck and ankle circumference. For the combined comparison of overweight/obese and normotensive/hypertensive adolescents (within the ANOVA) we therefore ignored sex as a factor. For the criteria of cardiometabolic syndrome sex-specific cut-offs for waist circumference were applied. Similarly, also the classification of overweight/obesity based on BMI and pre-hypertension/hypertension based on (the mean of the) BP readings was based on sex and age-specific cutoff scores. Missing data were not replaced. All data were analysed using SPSS (V.25.0, SPSS).

\section{RESULTS}

Two hundred and forty-eight children returned the signed consent form. Four children, who exceeded the age range were excluded. A total of 244 (188 female, 56 male) adolescents with a mean age of $14.4 \pm 1$ years (minmax: 13-16 years) met all inclusion and exclusion criteria and were enrolled in the study (figure 1). Ten children were classified as underweight (BMI $<5$ th percentile) and excluded from further analyses. Anthropometric data of two participants deviated largely and were also excluded to achieve sample appropriate measures. Analyses were hence based on a total of 232 adolescents (182 females, 50 males) for anthrompometry and haemodynamic parameters and for a subsample for serum plasma parameters.

\section{Prevalence of overweight/obesity and hypertension}

The prevalence of overweight and obesity $(\mathrm{O} / \mathrm{O})$ in the total sample ( $\mathrm{n}=232)$ was $33.0 \%$ (39 overweight, 36 obese), with $33.5 \%$ (61 of 182) in female adolescents and $28.0 \%$ (14 of 50) in male adolescents. Pre-hypertension and hypertension (pre-HT/HT) were present in more than one-third $(38.8 \%)$ of the study sample (36 pre-HT and $54 \mathrm{HT}$ of 232$)$, male $(38.0 \%)$ as well as female $(39.0 \%)$. When the data were analysed taking the body size status 
Table 1 Anthropometric and haemodynamic parameters in lean and overweight/obese adolescents classified using hypertension

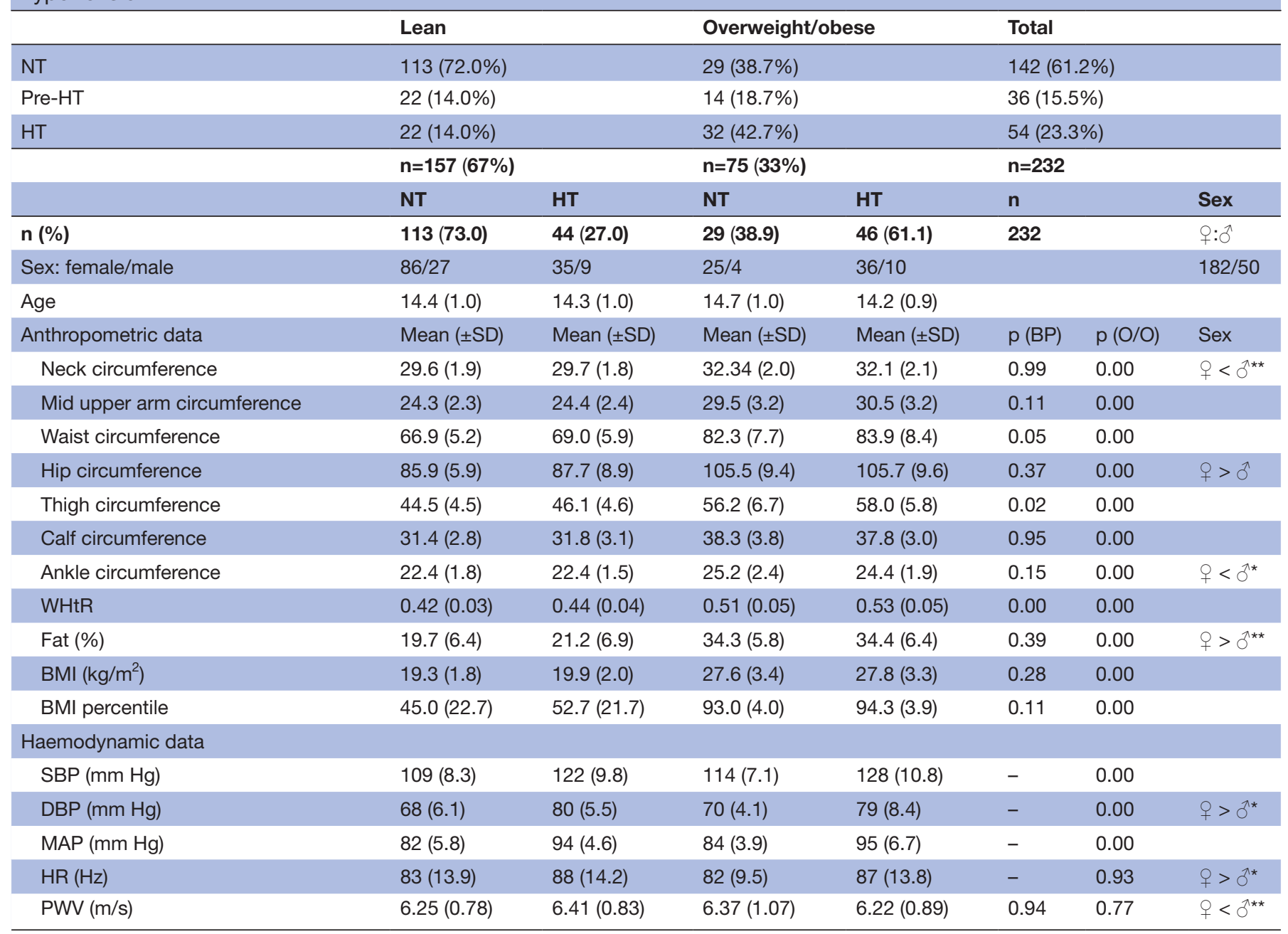

Classification of normotensive (NT) and (pre-)hypertensive (HT) based on mean systolic and diastolic blood pressure $(<90$ th/>90th) percentiles, respectively. Symbols $\left(+,{ }^{\circledR}\right)$ indicate significant sex differences in the given parameters $\left({ }^{*} p<0.05,{ }^{* *} p<0.01\right)$.

$\mathrm{BMI}$, body mass index; DBP, diastolic blood pressure; Fat\%, total body fat; HR, heart rate; MAP, mean arterial pressure; $p$ (BP), main effect for prehypertension/hypertension in a two-way; $\mathrm{P}(\mathrm{O} / \mathrm{O})$, main effect for overweight/obesity ANOVA; PWV, pulse wave velocity; SBP, systolic blood pressure; WHtR, waist to height ratio.

into account, a prevalence of even $61.1 \%$ (46 out of 75 ) pre-HT/HT in adolescents with $\mathrm{O} / \mathrm{O}$ and 27\% (44 out of 157) in lean adolescents was seen. Taken together, our data suggest that more than half of the adolescents $(52.0 \%$; 119 of 232) showed at least one risk factor for CVD (either hypertension, overweight/obesity or both (table 1).

\section{Anthropometric measures, haemodynamic parameters and sex differences}

Anthropometric measures were analysed by two-way ANOVA applying $\mathrm{O} / \mathrm{O}$ and pre-HT/HT as combined factors. Overweight/obesity was associated with significant differences in all anthropometric measures as well as total body fat (each $\mathrm{p}<0.001$, table 1$)$. Unique effect of BP was seen for waist $\left(F_{(1,230)}=3.79, \mathrm{p}=0.05\right)$, thigh circumference $\left(F_{(1,230)}=5.36, \mathrm{p}=0.02\right)$ and waist to height ratio (WHtR: $\left.F_{(1,230)}=14.3, \mathrm{p}<0.001\right)$. No significant interaction between $\mathrm{O} / \mathrm{O}$ and pre-HT/HT was found in any anthropometric measure (for means \pm SDs please refer to table 1). Higher systolic $\left(F_{(1,232)}=43.9, \mathrm{p}<0.001\right)$, diastolic $\left(F_{(1,232)}=11.6, \mathrm{p}=0.001\right)$ and mean arterial blood pressure $\left(F_{(1,232)}=29.6, \mathrm{p}<0.001\right)$ were found in adolescents with $\mathrm{O} / \mathrm{O}$ as compared to lean participants. Neither $\mathrm{O} / \mathrm{O}\left(F_{(1,}\right.$ $\left.{ }_{228}=0.09, \mathrm{p}=0.77\right)$ nor pre-HT $/ \mathrm{HT}\left(F_{(1,228)}=0.05, \mathrm{p}=0.95\right)$ showed significant differences in PWV.

Sex differences in anthropometric measures $\left(F_{(7,}\right.$ ${ }_{219}=11.9, \mathrm{p}<0.001$, Wilks' $\left.\lambda=0.72\right)$ were seen for neck $(f$ : $\left.30.0 \pm 2.0<m: 31.9 \pm 2.5 ; F_{(1,227)}=31.7, \mathrm{p}<0.001\right)$ and ankle circumference $\left(f: 22.9 \pm 2.0<m: 23.8 \pm 2.6 ; F_{(1,227)}=6.22\right.$, $\mathrm{p}=0.01)$. These parameters were both bigger in males. In females, a greater amount of total body fat $(f: 27.3 \pm 7.9$ $\left.>m: 15.5 \pm 7.8 ; \mathrm{t}_{(232)}=9.38, \mathrm{p}<0.001\right)$, higher heart rate $(f:$ $\left.87.4 \pm 13.1>m: 76.0 \pm 11.8 ; \mathrm{t}_{(232)}=5.56, \mathrm{p}<0.001\right)$ and DBP $\left(f: 73 \pm 7.7>m: 70 \pm 8.9 ; \mathrm{t}_{(232)}=2.53, \mathrm{p}=0.01\right)$ were observed, while $\mathrm{PWV}\left(f: 6.21 \pm 0.75<m: 6.59 \pm 1.1 ; \mathrm{t}_{(232)}=-2.77\right.$, $\mathrm{p}=0.006$ ) was significantly lower (table 1 ). 
Table 2 Lipid and glucose metabolism in lean and overweight/obese adolescents based on hypertension

\begin{tabular}{|c|c|c|c|c|c|c|}
\hline & \multicolumn{2}{|l|}{ Lean } & \multicolumn{2}{|c|}{ Overweight/obese } & \multirow[b]{2}{*}{ p (BP) } & \multirow[b]{2}{*}{$\mathrm{p}(\mathrm{O} / \mathrm{O})$} \\
\hline & NT & HT & NT & HT & & \\
\hline TG (mmol/L) & 0.77 (0.21), 99 & $0.81(0.26), 40$ & 0.87 (0.33), 25 & $1.14(0.55), 35$ & 0.012 & $<0.001$ \\
\hline TC (mmol/L) & 3.59 (0.81), 99 & 3.77 (0.90), 40 & $3.80(0.80), 25$ & 3.97 (0.79), 35 & 0.187 & 0.124 \\
\hline HDL-c (mmol/L) & 1.20 (0.53), 51 & 1.15 (0.38), 19 & 1.49 (1.7), 12 & $1.42(0.73), 16$ & 0.728 & 0.117 \\
\hline ADMA $(\mu \mathrm{g} / \mathrm{mL})$ & 1.50 (0.32), 74 & 1.46 (0.30), 24 & $1.34(0.34), 17$ & 1.46 (0.32), 22 & 0.604 & 0.220 \\
\hline Insulin (IU/L) & 22.7 (19.3), 73 & 26.7 (30.9), 24 & 30.8 (40.9), 15 & 40.4 (40.1), 21 & 0.178 & 0.244 \\
\hline HOMA-IR & 2.28 (1.3), 57 & 2.41 (1.9), 22 & $2.31(1.8), 12$ & $2.23(1.2), 15$ & 0.856 & 0.985 \\
\hline
\end{tabular}

$\mathrm{P}$ values indicate effects contributable either to overweight/obesity $(\mathrm{p}(\mathrm{O} / \mathrm{O}))$ or pre-hypertension/hypertension ( $\mathrm{p}(\mathrm{BP}))$ or both; values displayed are means $( \pm \mathrm{SD})$ and available $\mathrm{n}$.

ADMA, asymmetric dimethylarginine; FG, fasting glucose; HDL-c, high density lipoprotein cholesterol; HOMA-IR, homeostasis model assessment insulin resistance; HT, pre-hypertension/hypertension; NEFA, non-esterified free fatty acids; NO, nitric oxide; NT, normotensive; TC, total cholesterol; TG, triglycerides.

\section{Cardiometabolic and vascular plasma parameters}

Comparison of plasma parameters showed significantly higher levels of TGs in pre-HT/HT compared to normotensive (NT) adolescents $\left(F_{(1,198)}=6.46, \mathrm{p}=0.012\right)$, and independently in $\mathrm{O} / \mathrm{O}$ as compared to lean participants $\left(F_{(1,198)}=13.34, \mathrm{p}<0.001\right)$. Higher FG was found in pre$\mathrm{HT} / \mathrm{HT}$ as compared to normotensive adolescents $\left(F_{(1,}\right.$ $\left.{ }_{202}=4.34, \mathrm{p}=0.039\right)$; this was independent of body size status. None of the other parameters reached statistical significance in a groupwise comparison (for means \pm SDs please refer to table 2).

\section{Assessment of cardiometabolic risk factors}

The prevalence of cardiometabolic syndrome based on the definition of Cook $e t a l^{37} 38$ is shown in table 3. For a subsample of 90 adolescents, complete data were available. The data showed a prevalence of at least one risk factor in $45.6 \%$ of the adolescents, two risk factors in $20.0 \%$ and three risk factors in $7.8 \%$.

The levels of HOMA-IR were elevated $(>2.0)$ in almost half of the sample $46.2 \%\left(\chi_{(1)}^{2}=0.604, \mathrm{p}=0.437\right)$. ADMA $>50$ th percentile was elevated in $27.0 \%$ of adolescents $\left(\chi_{(1)}^{2}=29.0, \mathrm{p}<0.001\right)$. Adolescents with ADMA $>50$ th percentile had higher DBP and PWV and a tendency towards a lower NO $(p=0.057)$ (table 3$)$. Endothelial dysfunction, defined as PWV exceeding the critical threshold above the 50th percentile, was present in more than one-quarter $(25.9 \%)$ of the total sample $\left(\chi_{(1)}^{2}=53.1\right.$, $\mathrm{p}<0.001$, table 3). Participants with $\mathrm{PWV}>50$ th percentile had significantly higher SBP $\left(\mathrm{t}_{(227)}=-2.85, \mathrm{p}=0.005\right)$ and ADMA $\left(\mathrm{t}_{(135)}=-1.92, \mathrm{p}=0.053\right)$ as compared to participants with $\mathrm{PWV}<50$ th percentile (table 3 ).

\section{Predicting vascular dysfunction}

Multiple linear regression was conducted to predict PWV by stepwise inclusion of age, SBP, BMI, TGs, FG, TC and serum ADMA. ADMA, SBP and TGs were able to significantly predict PWV $\left(F_{(3,125)}=8.78, \mathrm{p}<0.001\right)$. The $\mathrm{R}^{2}$ for the overall model was 0.178 (adjusted $\mathrm{R}^{2}{ }_{\text {(adj) }}=0.157$ ), indicating a moderate goodness of fit (table 4). Participants predicted PWV is equal to 0.572 (ADMA) +0.023 $(\mathrm{SBP})+(-0.546)(\mathrm{TG})+3.195$. Accordingly, the highest variance is explained by serum ADMA and SBP while a negative association was seen with TGs.

\section{DISCUSSION}

The present study indicates a high prevalence of cardiometabolic risk factors, identifying more than half of the 13-16year old South African adolescents with at least one major risk factor for CVD, either overweight/ obesity $(12.5 \%)$, hypertension $(19.0 \%)$ or both $(19.8 \%)$. More than one-third of the adolescents $(38.8 \%)$ were classified as pre-HT/HT and one-third $(33.0 \%)$ as O/O. Among adolescents with $\mathrm{O} / \mathrm{O}$, the prevalence of pre-HT/ HT was almost two-thirds $(61.1 \%)$. Observed prevalences confirm previous findings ${ }^{193}$ and in agreement with existing literature, hyperlipidaemia and hyperglycaemia were again identified as key metabolic risk factors in the development of hypertension. ${ }^{37} 39$ Anthropometric measures were consistently higher in $\mathrm{O} / \mathrm{O}$ adolescents, but also hypertension contributed towards differences in thigh circumference and WHtR. The prevalence of pre-HT/HT in lean adolescents (27.4\%) further emphasises that $\mathrm{O} / \mathrm{O}$ plays a decisive, though not an exclusive role in the development of hypertension. ${ }^{40-42}$

PWV as an indicator for arterial stiffness was generally higher as compared to known reference values for healthy children and adolescents. ${ }^{32}$ Our results confirmed previous findings that PWV is higher in male adolescents as compared to female adolescents. ${ }^{29}{ }^{31}$ Using PWV $>50$ th percentile as an early indicator for endothelial dysfunction, allowed us to draw important conclusions. For example, adolescents with $\mathrm{PWV}>50$ th percentile had significantly higher systolic blood pressure and ADMA levels compared 
Open access

Table 3 Criteria for cardiometabolic syndrome, insulin resistance and parameters of vascular functioning

\section{Criteria}

\begin{tabular}{|c|c|c|c|}
\hline \multirow[t]{2}{*}{ Central obesity } & $W C<90$ th $p c$ & WC >90th pc & $n$ \\
\hline & 205 (89.9\%) & $23(10.1 \%)$ & 228 \\
\hline \multirow[t]{2}{*}{ Pre-HT/HT } & $\mathrm{BP}<90$ th $\mathrm{pc}$ & BP >90th pc & \\
\hline & $142(61.7 \%)$ & $88(38.3 \%)$ & 230 \\
\hline \multirow[t]{2}{*}{ Hypertriglyceridaemia } & $\mathrm{TG}<110 \mathrm{mg} / \mathrm{dL}$ & $\mathrm{TG}>110 \mathrm{mg} / \mathrm{dL}$ & \\
\hline & $179(89.9 \%)$ & $20(10.1 \%)$ & 199 \\
\hline \multirow[t]{2}{*}{ Impaired glucose } & $\mathrm{FG}<110 \mathrm{mg} / \mathrm{dL}$ & $\mathrm{FG}>110 \mathrm{mg} / \mathrm{dL}$ & \\
\hline & $196(97.0 \%)$ & $6(3.0 \%)$ & 202 \\
\hline \multirow[t]{2}{*}{ Low HDL-c } & $\mathrm{HDL}>40 \mathrm{mg} / \mathrm{dL}$ & $\mathrm{HDL} \leq 40 \mathrm{mg} / \mathrm{dL}$ & \\
\hline & $43(43.9 \%)$ & 55 (56.1\%) & 98 \\
\hline Risk factors combined & \multicolumn{3}{|c|}{ WC $>90$ th $p c, B P>90$ th $p c, T G>110 \mathrm{mg} / \mathrm{dL}, \mathrm{FG}>100 \mathrm{mg} / \mathrm{dL}, \mathrm{HDL} \leq 40 \mathrm{mg} / \mathrm{dL}$} \\
\hline 1 criteria & \multicolumn{2}{|c|}{$41 / 90(45.6 \%)$} & \\
\hline 2 criteria & \multicolumn{2}{|c|}{$18 / 90(20.0 \%)$} & \\
\hline$\geq 3$ criteria & \multicolumn{2}{|c|}{$7 / 90(7.8 \%)$} & \\
\hline \multirow[t]{2}{*}{ HOMA-IR } & HOMA-IR $<2.0$ & HOMA-IR $>2.0$ & 106 \\
\hline & $57(53.8 \%)$ & $49(46.2 \%)$ & \\
\hline \multirow[t]{4}{*}{ ADMA } & ADMA $<50$ th pc & ADMA $>50$ th pc & 137 \\
\hline & $100(73.0 \%)$ & $37(27.0 \%)$ & \\
\hline & $\nabla$ & $\nabla$ & \\
\hline & Mean $( \pm \mathrm{SD})$ & Mean $( \pm \mathrm{SD})$ & $P$ value \\
\hline DBP & $72( \pm 7.3)$ & $75( \pm 7.6)$ & 0.038 \\
\hline PWV & $6.10( \pm 0.78)$ & $6.52( \pm 0.97)$ & 0.009 \\
\hline NO & $2.79( \pm 1.2)$ & $2.30( \pm 1.0)$ & 0.076 \\
\hline \multirow[t]{4}{*}{ PWV } & PWV <50th pc & PWV >50th pc & 228 \\
\hline & 169 (74.1\%) & $59(25.9 \%)$ & \\
\hline & $\nabla$ & $\nabla$ & \\
\hline & Mean $( \pm S D)$ & Mean $( \pm \mathrm{SD})$ & $P$ value \\
\hline SBP & $114(12.0)$ & $119(11.2)$ & $0.005^{\star \star}$ \\
\hline ADMA & $1.44(0.30)$ & $1.57(0.37)$ & 0.057 \\
\hline
\end{tabular}

Mean $( \pm \mathrm{SD})$ of parameters comparing adolescents with $\mathrm{PWV}<$ or $>$ the 50 th percentile. ${ }^{*} \mathrm{p}<0.05,{ }^{* *} \mathrm{p}<0.01$

ADMA, asymmetric dimethylarginine; DBP, diastolic blood pressure; FG, fasting glucose; HDL-c, high density lipoprotein cholesterol; HOMA-IR, homoeostasis model assessment index; HR, heart rate; MAP, mean arterial pressure; NO, nitric oxide; pc, percentile; Pre-HT/HT, pre-hypertension/hypertension; PWV, pulse wave velocity; SBP, systolic blood pressure; TG, triglycerides; WC, waist circumference.

to adolescents with $\mathrm{PWV}<50$ th percentile. As these findings were obtained by multiple linear regression analyses, they suggest a moderate prediction of PWV by ADMA and SBP. In the given sample of adolescents, NO tended to be lower in hypertensive as compared to normotensive young subjects.

ADMA was shown to influence changes in systolic and diastolic blood pressure from childhood to adolescence. ${ }^{23}$

Table 4 Summary of the multiple linear regression analysis to predict PWV

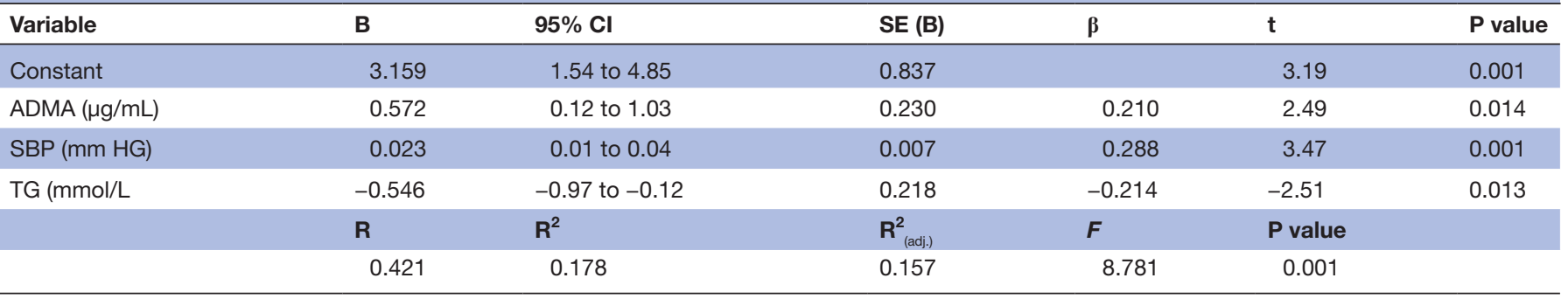

Multiple linear regression conducted to predict PWV (predictors excluded from model: age, BMI, fasting glucose, total cholesterol).

ADMA, asymmetric dimethylarginine; BMI, body mass index; PWV, pulse wave velocity; SBP, systolic blood pressure; TG, triglycerides. 
In agreement with other studies ${ }^{43}{ }^{44}$ ADMA and hypertension might therefore be regarded as main risk factors for endothelial dysfunction, and in adolescents, as an early sign of vascular damage. The vascular damage can be measured non-invasively via PWV measurements.

Hypertension was also observed in lean adolescents, suggesting a different pathogenesis. ${ }^{45}$ Insulin resistance (IR) is generally associated with overweight and obesity, increasing the vulnerability to metabolic syndrome. ${ }^{6}$ However, not all $\mathrm{O} / \mathrm{O}$ children have IR and IR may also occur in lean children. ${ }^{46}$ According to the International Diabetes Foundation, the HOMA-IR threshold for adults is $\geq 1.6$, although increased values are reported during adolescence. ${ }^{47}$ It has been reported that puberty is accompanied by a physiological state that favours IR. ${ }^{35}$ Our results also confirm this. We observed higher thresholds of HOMA-IR (mean values between 1.91 and 2.37, table 2) and a high prevalence $(44.5 \%)$ of raised values (HOMA-IR $>2.0$ ), in both lean and $\mathrm{O} / \mathrm{O}$ as well as normotensive and hypertensive adolescents. Our data suggest that overweight and obesity are not the only necessary prerequisites for the development of IR in adolescence, and some other factors (eg, epigenetic) may contribute towards development of hypertension in lean adolescents. Elevated fasting insulin and NEFA in lean hypertensive young men has previously been reported by Penesova $e t$ al . Our data did not confirm this. However, this could be attributed to the fact that our participants were much younger and included both sexes. ${ }^{45}$

\section{Limitations}

Our study has several limitations. One limitation of our study is its cross-sectional character. To study the progression of vascular damage, longitudinal studies over longer periods using repeated measures on the same subjects are required. Furthermore, hypertension in our study was classified based on the mean BP of three readings at one time and, therefore, might be overestimated. In young study participants, and in particular during medical examinations, BP could be increased. Hence, recording of 24-hour BP might provide a more valid estimate and this should be encouraged in future studies.

Behavioural risk factors such as physical inactivity ${ }^{48}$ and unhealthy diets were not assessed in our study. As these risk factors are related to $\mathrm{O} / \mathrm{O}$ and hypertension, future studies should examine these aspects in detail.

\section{CONCLUSIONS}

Hypertension and obesity, acting either independently or in combination, contribute to a high risk for cardiometabolic syndrome and endothelial dysfunction in 13-16year old adolescents in rural South Africa. SBP and plasma ADMA were identified as the main determinants for elevated measures of PWV, suggesting a trend towards development of vascular dysfunction.

Close monitoring of cardiometabolic risk factors and the implementation of preventive strategies are urgently needed in these underprivileged groups of adolescents. ${ }^{49}$ Future studies should, in addition, examine the association of behavioural risk factors such as physical inactivity, unhealthy diets and early usage of alcohol and cigarette consumption and their relationship with known cardiometabolic risk factors.

\section{Author affiliations}

${ }^{1}$ Department of Human Biology, Faculty of Health Sciences, Walter Sisulu University, Mthatha, Eastern Cape, South Africa

${ }^{2}$ Physiology Division, Otto Loewi Research Center for Vascular Biology, Immunology and Inflammation, Medical University of Graz, Graz, Austria

${ }^{3}$ Department of Biological and Environmental Sciences, Faculty of Natural Sciences, Walter Sisulu University, Mthatha, Eastern Cape, South Africa

${ }^{4}$ School of Health Sciences, Kristiania University College, Oslo, Norway

Acknowledgements We wish to thank the adolescents for participating in the study.

Contributors NG and BN-C conceived the study, obtained funding, supervised data collection, interpreted the data and made a critical revision of the manuscript. BPL, $\mathrm{BB}, \mathrm{ENM}, \mathrm{FK}, \mathrm{NO}, \mathrm{MG}$ and CS-R carried out the study, collected data in the field and performed data entry. BPL, GAE and KS-Z performed statistical analyses and interpretation and wrote the manuscript. NG, BN-C and PMF gave final approval. All listed authors meet the criteria for authorship, were involved in writing the paper and had final approval of the submitted and published version.

Funding The study was supported by the South African National Research Foundation IRG - South Africa/Austria Joint Scientific and Technology Cooperation Programme and the Österreichische Agentur für internationale Mobilität und Kooperation in Bildung, Wissenschaft und Forschung, OeAD GmbH (ÖAD, Nr. 7689), Vienna, Austria.

Competing interests None declared.

Patient consent for publication Not required.

Ethics approval The study was conducted according to the Declaration of Helsinki (2013) and local and national regulations in South Africa. Ethical approval was obtained from the Health Sciences Ethics Committee of Walter Sisulu University, South Africa (Ref No: 045/2018). Written informed consent was obtained from adolescents and their parents/legal guardians for voluntary participation. The study adhered to the standards of reporting and in accordance with the National Data Protection Acts.

Provenance and peer review Not commissioned; externally peer reviewed.

Data availability statement Data are available upon reasonable request. Deidentified individual data collected during the trial including the study protocol will be shared with researchers who provide a methodologically sound proposal immediately after publication. Proposals and requests should be sent to the corresponding author.

Open access This is an open access article distributed in accordance with the Creative Commons Attribution Non Commercial (CC BY-NC 4.0) license, which permits others to distribute, remix, adapt, build upon this work non-commercially, and license their derivative works on different terms, provided the original work is properly cited, appropriate credit is given, any changes made indicated, and the use is non-commercial. See: http://creativecommons.org/licenses/by-nc/4.0/.

ORCID iD

Karin Schmid-Zalaudek http://orcid.org/0000-0002-3422-0031

\section{REFERENCES}

1 WHO. Cardiovascular diseases (CVDs), fact sheet. [webpage], 2015. Available: http://www.who.int/mediacentre/factsheets/Fs317/en/: World Health Organisation

2 WHO. Obesity and overweight, 2019. Available: http://who.imt/ mediacentre/factsheets/fs311/en/2016

3 WHO. Noncommunicable diseases, 2018. Available: https://www. who.int/news-room/fact-sheets/detail/noncommunicable-diseases

4 WHO. Seventieth world heaith assembly: report of the commission on ending childhood obesity: implementation plan, 2017. Available: https://apps.who.int/gb/ebwha/pdf_files/WHA70/A70_31-en.pdf 
5 Shayo FK. Co-Occurrence of risk factors for non-communicable diseases among in-school adolescents in Tanzania: an example of a low-income setting of sub-Saharan Africa for adolescence health policy actions. BMC Public Health 2019:19:972.

6 O'Neill S, O'Driscoll L. Metabolic syndrome: a closer look at the growing epidemic and its associated pathologies. Obes Rev 2015;16:1-12.

7 Bruyndonckx L, Hoymans VY, Lemmens K, et al. Childhood obesityrelated endothelial dysfunction: an update on pathophysiological mechanisms and diagnostic advancements. Pediatr Res 2016;79:831-7.

8 Farrag NS, Cheskin LJ, Farag MK. A systematic review of childhood obesity in the middle East and North Africa (Mena) region: prevalence and risk factors meta-analysis. Adv Pediatr Res 2017;4. doi:10.12715/apr.2017.4.8. [Epub ahead of print: 15 Jun 2017].

9 Kimani-Murage EW, Kahn K, Pettifor JM, et al. The prevalence of stunting, overweight and obesity, and metabolic disease risk in rural South African children. BMC Public Health 2010;10:158.

10 Nkeh-Chungag BN, Sekokotla AM, Sewani-Rusike C, et al. Prevalence of hypertension and pre-hypertension in 13-17 year old adolescents living in Mthatha - South Africa: a cross-sectional study. Cent Eur J Public Health 2015;23:59-64.

11 Sekokotla MA, Goswami N, Sewani-Rusike CR, et al. Prevalence of metabolic syndrome in adolescents living in Mthatha, South Africa. Ther Clin Risk Manag 2017;13:131-7.

12 Adeloye D, Basquill C. Estimating the prevalence and awareness rates of hypertension in Africa: a systematic analysis. PLOS One 2014;9::e104300.

13 Unicef, WHO. Levels and trends in child malnutrition: key findings of the 2018 edition of the joint child malnutrition estimates, 2018. Available: https://www.who.int/nutgrowthdb/2018-jme-brochure.pdf

14 Santi M, Simonetti BG, Leoni-Foglia CFP, et al. Arterial hypertension in children. Curr Opin Cardiol 2015;30:403-10.

15 Noubiap JJ, Essouma M, Bigna JJ, et al. Prevalence of elevated blood pressure in children and adolescents in Africa: a systematic review and meta-analysis. Lancet Public Health 2017;2:e375-86.

16 Ataklte F, Erqou S, Kaptoge S, et al. Burden of undiagnosed hypertension in sub-Saharan Africa: a systematic review and metaanalysis. Hypertension 2015;65:291-8.

17 Guwatudde D, Nankya-Mutyoba J, Kalyesubula R, et al. The burden of hypertension in sub-Saharan Africa: a four-country cross sectional study. BMC Public Health 2015;15:1211.

18 de Moraes ACF, Lacerda MB, Moreno LA, et al. Prevalence of high blood pressure in 122,053 adolescents: a systematic review and meta-regression. Medicine 2014;93:e232.

19 Bhimma R, Naicker E, Gounden V, et al. Prevalence of primary hypertension and risk factors in grade XII learners in KwaZulu-Natal, South Africa. Int J Hypertens 2018;2018:1-9.

20 Redwine KM, Acosta AA, Poffenbarger T, et al. Development of hypertension in adolescents with pre-hypertension. J Pediatr 2012;160:98-103.

21 Chiolero A, Bovet P, Paradis G. Screening for elevated blood pressure in children and adolescents: a critical appraisal. JAMA Pediatr 2013;167:266-73.

22 Juonala M, Viikari JSA, Rönnemaa T, et al. Elevated blood pressure in adolescent boys predicts endothelial dysfunction: the cardiovascular risk in young Finns study. Hypertension 2006;48:424-30.

23 de Giorgis T, Marcovecchio ML, Giannini C, et al. Blood pressure from childhood to adolescence in obese youths in relation to insulin resistance and asymmetric dimethylarginine. $J$ Endocrinol Invest 2016;39:169-76.

24 Rajendran P, Rengarajan T, Thangavel J, et al. The vascular endothelium and human diseases. Int J Biol Sci 2013;9:1057-69.

25 De Mey JGR, Vanhoutte PM. End O' the line revisited: moving on from nitric oxide to CGRP. Life Sci 2014;118:120-8.

26 Daiber A, Steven S, Weber A, et al. Targeting vascular (endothelial) dysfunction. Br J Pharmacol 2017:174:1591-619.

27 Widmer RJ, Lerman A. Endothelial dysfunction and cardiovascular disease. Glob Cardiol Sci Pract 2014:2014:43.

28 Yamashina A, Tomiyama H, Arai T, et al. Brachial-ankle pulse wave velocity as a marker of atherosclerotic vascular damage and cardiovascular risk. Hypertens Res 2003;26:615-22.
29 Thurn D, Doyon A, Sözeri B, et al. Aortic pulse wave velocity in healthy children and adolescents: reference values for the Vicorder device and modifying factors. Am J Hypertens 2015;28:1480-8.

30 Cote AT, Phillips AA, Harris KC, et al. Obesity and arterial stiffness in children: systematic review and meta-analysis. Arterioscler Thromb Vasc Biol 2015;35:1038-44

31 Silva ABT, Capingana DP, Magalhães $P$, et al. Predictors and reference values of pulse wave velocity in prepubertal Angolan children. J Clin Hypertens 2016;18:725-32.

32 Schutte AE, Kruger R, Gafane-Matemane LF, et al. Ethnicity and arterial stiffness. Arterioscler Thromb Vasc Biol 2020;40:1044-54.

33 Matjuda EN, Engwa GA, Letswalo PB, et al. Association of hypertension and obesity with risk factors of cardiovascular diseases in children aged 6-9 years old in the eastern Cape Province of South Africa. Children 2020;7:25

34 Stewart A, Marfell-Jones M, Olds T. International standards for anthropometric assessment. Lower Hutt: ISAK, 2011.

35 Goran MI, Gower BA. Longitudinal study on pubertal insulin resistance. Diabetes 2001;50:2444-50.

36 Ostchega Y, Prineas RJ, Paulose-Ram R, et al. National health and nutrition examination survey 1999-2000: effect of observer training and protocol standardization on reducing blood pressure measurement error. J Clin Epidemiol 2003;56:768-74.

37 Cook S, Weitzman M, Auinger P, et al. Prevalence of a metabolic syndrome phenotype in adolescents: findings from the third National health and nutrition examination survey, 1988-1994. Arch Pediatr Adolesc Med 2003;157:821-7.

38 Reisinger C, Nkeh-Chungag BN, Fredriksen PM, et al. The prevalence of pediatric metabolic syndrome-a critical look on the discrepancies between definitions and its clinical importance. Int $J$ Obes 2021:45:12-24.

39 Mudie K, Jin MM, Kendall L. Non-Communicable diseases in subSaharan Africa: a scoping review of large cohort studies. J Glob Health 2019:9:020409.

40 Kapoor N, Lotfaliany M, Sathish T, et al. Prevalence of normal weight obesity and its associated cardio-metabolic risk factors - Results from the baseline data of the Kerala Diabetes Prevention Program (KDPP). PLoS One 2020;15:e0237974.

41 Raphadu TT, Staden MV, Dibakwane WM, et al. A non-invasive investigation into the prevalence of higher than normal blood pressure, hypertension and the association between blood pressure and body weight in male and female adolescents in the Polokwane local Municipality, Limpopo-South Africa: a cross-sectional study. Children 2020;7. doi:10.3390/children7030018. [Epub ahead of print: 0403 2020].

42 Chait A, den Hartigh LJ, Distribution AT. Adipose tissue distribution, inflammation and its metabolic consequences, including diabetes and cardiovascular disease. Front Cardiovasc Med 2020;7:22

43 Maldonado J, Pereira T, Sousa F, et al. Determinants of aortic pulse wave velocity in Portuguese children and adolescents - an update from the Portuguese vascular phenotype in children and adolescents (PORT-VASPH) cohort. J Hypertens 2019;37:e32.

44 Hudson L, Kinra S, Wong I, et al. Is arterial stiffening associated with adiposity, severity of obesity and other contemporary cardiometabolic markers in a community sample of adolescents with obesity in the UK? BMJ Paediatr Open 2017;1:e000061.

45 Penesova A, Cizmarova E, Belan V, et al. Insulin resistance in young, lean male subjects with essential hypertension. J Hum Hypertens 2011;25:391-400.

46 Tagi VM, Giannini C, Chiarelli F. Insulin resistance in children. Front Endocrinol 2019:10:342.

47 Esteghamati A, Ashraf $\mathrm{H}$, Khalilzadeh O, et al. Optimal cut-off of homeostasis model assessment of insulin resistance (HOMA-IR) for the diagnosis of metabolic syndrome: third national surveillance of risk factors of non-communicable diseases in Iran (SuRFNCD-2007). Nutr Metab 2010:7:26.

48 Moser O, Eckstein ML, West DJ, et al. Type 1 diabetes and physical exercise: moving (forward) as an adjuvant therapy. Curr Pharm Des 2020;26:946-57.

49 Kagura J, Ong KK, Adair LS, et al. Paediatric hypertension in South Africa: an underestimated problem calling for action. $S$ Afr Med $J$ 2018;108:708-9. 